OPEN ACCESS

Edited by:

Javier Carrasco,

CIC EnergiGUNE, Spain

Reviewed by:

Chunyang Nie,

Guangdong University of

Technology, China

Alain Tressaud

UMR5026 Institut de Chimie de la

Matière Condensée de Bordeaux

(ICMCB), France

*Correspondence:

Leticia F. Velasco

leticia.fernandezvelasco@mil.be

Specialty section:

This article was submitted to

Physical Chemistry and Chemical

Physics,

a section of the journal

Frontiers in Chemistry

Received: 11 August 2020 Accepted: 25 November 2020

Published: 06 January 2021

Citation:

Velasco LF, Kim KH, Lee Y-S and Lodewyckx P (2021) Influence of Fluorine Doping of Activated Carbon

Fibers on Their Water Vapor

Adsorption Characteristics.

Front. Chem. 8:593756.

doi: 10.3389/fchem.2020.593756

\section{Influence of Fluorine Doping of Activated Carbon Fibers on Their Water Vapor Adsorption Characteristics}

\author{
Leticia F. Velasco ${ }^{*}$, Kyung Hoon Kim ${ }^{2}$, Young-Seak Lee ${ }^{2}$ and Peter Lodewyckx ${ }^{1}$ \\ ${ }^{1}$ Department of Chemistry, Royal Military Academy, Brussels, Belgium, ${ }^{2}$ Department of Chemical Engineering and Applied \\ Chemistry, Chungnam National University, Daejeon, South Korea
}

The characterization of fluorinated carbon fibers by water sorption has been broadly investigated in this work. In brief, a pitch-based activated carbon fiber (ACF) was submitted to a fluorination process under different conditions of partial pressure $\left(\mathrm{F}_{2}: \mathrm{N}_{2}\right.$ ratio) and temperature. This led to samples with varied fluorine content and C-F type bonding. The effect of the fluorination treatment on the textural properties of the ACF was studied by means of nitrogen and carbon dioxide adsorption at -196 and $0^{\circ} \mathrm{C}$, respectively, while the changes induced in the surface chemistry of the materials were analyzed by XPS. Also, the affinity and stability of the materials toward water was evaluated by single and cycling isotherms. The obtained results show that a mild fluorination not only can preserve most of the textural properties of the parent ACF, but enhance the water uptake at the first stages of the water sorption process, together with a shift in the upswing of the water isotherms toward lower relative humidities. This indicates that fluorination under certain conditions can actually enhance the surface hydrophilicity of carbon materials with specific properties. On the contrary, higher partial pressures led to highly fluorinated fibers with lower porosity and more hydrophobic character. Moreover, they presented a lower chemical stability as demonstrated by a change in the shape of the water isotherms after two consecutive measurements. The kinetics of water sorption in the ACFs provided further insights into the different sorption phenomena involved. Hence, water sorption can definitely help to tailor the water affinity, stability and performance of fluorinated porous carbon materials under humid conditions.

Keywords: water sorption, fluorine doping, activated carbon fibers, surface chemistry, hydrophilicity

\section{INTRODUCTION}

The mechanisms of water sorption in carbon pores have been the subject of extensive study during the last years (Liu et al., 2017). Hence, as the process gets better understood, the use of water isotherms for the characterization of porous carbon materials is gaining interest. This is mainly due to its advantages over other adsorbates: it can be performed at room temperature, water has a very small kinetic diameter $(0.28 \mathrm{~nm})$ which allows it to enter pores even smaller than those accessible to $\mathrm{CO}_{2}$ (Lodewyckx, 2010) and it gives information about both the textural and surface properties of the material. In spite of this, the potential of this technique is still far from being fully explored. 
It is well-established that water sorption is sensitive to surface chemistry (Bandosz et al., 1996; Thommes et al., 2011; Tóth and Lászlo, 2012; Lodewyckx et al., 2013; Nguyen et al., 2014). More specifically, it is assumed that water adsorption in carbon nanomaterials first proceeds through the clustering of water molecules around primary adsorption sites (functional surface groups). Thus, the overall shape of the water isotherm, and more particularly the first part, can give important information about the surface composition, which is a crucial feature for the performance of the material under realistic conditions of humidity.

The doping of carbon materials with heteroelements is known to be an effective approach to tailor their hydrophilic/hydrophobic character and consequently their water adsorption behavior (Lee et al., 2007; Kumar et al., 2016). In this regard, fluorinated porous carbonaceous materials are receiving increasing attention due to their promising performance in several fields such as gas adsorption, gas sensors or energy storage (Touhara and Okino, 2000; Park et al., 2016; Kim et al., 2018; Wang et al., 2020) and they can even be considered as a new class of materials (Matei Ghimbeu et al., 2015; Shahtalebi et al., 2016). In the specific case of activated carbon fibers, fluorination has proven effective for improving their electrochemical properties (Shao et al., 2016) as well as the methane storage capacity (Im et al., 2009), $\mathrm{CO}_{2}$ adsorption (Sugiyama and Hattori, 2020), and even for biomedical applications (Sun et al., 2017). Nevertheless, the mechanisms of the fluorination process and their impact on the final properties of the material are still under debate. To illustrate this, it has to be first mentioned that it has been traditionally accepted that fluorination of porous carbons increases their hydrophobicity due to the repulsive nature of the fluorine atoms and/or the hindering of the water cluster formation ( $\mathrm{Li}$ et al., 1995; Setoyama et al., 1996; Parmentier et al., 2012; Liu et al., 2019). However, recent simulation and experimental investigations on silicon carbide derived nanoporous carbons pointed toward a less straightforward and dual scenario (Farmahini et al., 2015; Shahtalebi et al., 2016). This two-fold behavior apparently arises from the fact that fluorination indeed generates more hydrophilic carbon surfaces but at the same time enhances the energy barriers for water sorption. The apparent discrepancies between these results may arise from the great number of variables involved. It has to be taken into account that besides the fluorination conditions (fluorine agent, temperature, reaction time...), the final chemical composition, as well as the structure of the products obtained by fluorination, are dependent on the structure and characteristics of the starting material (e.g. degree of graphitization, structural order, dimensions of the particles, surface curvature, purity...) (Lee et al., 2007; Matei Ghimbeu et al., 2015).

In this context, the present work aims at further investigating the role of fluorine doping on the experimental water sorption behavior of activated carbon fibers. To attain this goal, a pitchbased activated carbon fiber was submitted to a fluorination treatment under different conditions of partial pressure and temperature. The textural and surface properties of the soobtained materials were characterized by means of gas sorption and XPS, while their water sorption behavior and stability was deeply investigated by single and consecutive water isotherms. The gathered results stress the importance of adequately choosing the fluorination treatment variables, since a small variation can lead to materials with quite different properties. Understanding how fluorine doping can variously change the features of ACFs is of particular importance in order to design materials with improved performances in function of the intended applications.

\section{EXPERIMENTAL}

\section{Fluorination of the ACFs}

Commercial pitch-based activated carbon fiber (Ad'all A-10, Osaka gas Co Ltd) was used as raw material and denoted as sample E. The surface fluorination of ACFs was performed by direct fluorination. This method has received a substantial attention because of its potential for uniform modification, short reaction time, low cost, and efficiency (Lee et al., 2007). The reaction between activated carbon fibers and fluorine is exothermic. To control the rate of fluorination and allow the heat of reaction to dissipate, $\mathrm{F}_{2}-\mathrm{N}_{2}$ gas mixture was used at low temperatures.

The fluorination device consisted of a reactor, a vacuum pump and a buffer tank connected to gas cylinders. The samples (around $400 \mathrm{mg}$ ) were loaded into a fluorine-passivated nickel reactor and degassed at $373 \mathrm{~K}$ for $1 \mathrm{~h}$ to remove moisture. Then diluted fluorine was introduced into the reactor at a very low flow. Nitrogen gas (99.999\%) and fluorine gas (99.8\%, Messer Grieheim $\mathrm{GmbH}$ ) were used during the fluorination process. Fluorination was performed at room temperature and 1 bar for 10 min at three different $F_{2}: N_{2}$ gas volume ratios: $1: 9,3: 7$, and 5:5, thus obtaining ACFs A, B and C. After the reaction, the reaction vessel was then pumped out again to $10 \mathrm{mTorr}$ with subsequent nitrogen gas purge prior to the extraction of the fibers. An additional sample (ACF D) was prepared introducing the $\mathrm{F}_{2}-\mathrm{N}_{2}$ mixture with a partial pressure of 3:7 and then heating the reactor to $150^{\circ} \mathrm{C}$. The comparison of the results obtained for fibers $\mathrm{B}$ and $\mathrm{D}$ will allow to study the effect of the fluorination temperature on the water sorption behavior as well.

\section{Characterization of the ACFs}

\section{Nitrogen and Carbon Dioxide Sorption Isotherms}

Nitrogen and carbon dioxide isotherms at -196 and $0^{\circ} \mathrm{C}$, respectively, were performed in an Autosorb-1 device (Quantachrome Instruments). The $\mathrm{N}_{2}$ isotherms were used to calculate the BET specific surface area $\left(\mathrm{S}_{\mathrm{BET}}\right)$, micropore volume $\left(\mathrm{V}_{\text {micropore}}\right.$, calculated by the Dubinin-Radushkevich (DR) equation) and total pore volume $\left(\mathrm{V}_{\mathrm{t}}\right.$ at $\mathrm{p} / \mathrm{p}_{0}$ at 0.99$)$. The volume of pores smaller than $0.7 \mathrm{~nm}\left(\mathrm{~W}_{0}\right)$ was assessed from the $\mathrm{CO}_{2}$ adsorption isotherms with the DR equation. The samples were degassed overnight at $150^{\circ} \mathrm{C}$ prior to the sorption measurements. On this subject, several outgassing temperatures were investigated in order to find the optimal one (i.e., to guarantee a proper cleaning of the surface to allow the diffusion of the gas, while minimizing the modification of the original material). The extent of the influence of this variable was directly proportional to the degree of fluorination of the material. 


\section{X-Ray Photoelectron Spectroscopy (XPS)}

A MultiLab 2000 spectrometer (Thermo Electron Corporation, $\mathrm{UK})$ was used to identify the elements present in the external surface $(<10 \mathrm{~nm})$ of the fibers. Aluminum $\mathrm{K} \alpha(1485.6 \mathrm{eV})$ radiation was used as the $\mathrm{X}$-ray source, and an anode voltage of $14.9 \mathrm{keV}$, a filament current of $4.6 \mathrm{~A}$, and an emission current of a $20 \mathrm{~mA}$ were applied. All samples were treated at $10^{-12}$ bar to remove impurities. Survey spectra were obtained at a pass energy of $50 \mathrm{eV}$ in increments of $0.5 \mathrm{eV}$.

\section{Water Sorption}

Water sorption isotherms were measured at $20^{\circ} \mathrm{C}$ using a gravimetric water sorption analyzer (Aquadyne DVS, Quantachrome Instruments). Each point of the gravimetric isotherm was obtained after an equilibrium time corresponding to $0.0004 \%$ of the mass change per minute at a given relative humidity. In order to check the stability of the materials after the exposure to humidity, cycling isotherm were also measured for all the materials. This means that after the first water adsorptiondesorption cycle, the sample was kept in the analysis device and immediately submitted to at least one additional identical cycle. Since water is sensitive to the surface groups of the materials, mild outgassing conditions $\left(100^{\circ} \mathrm{C}\right.$, overnight $)$ were used. This guarantees an optimal compromise between the cleaning of the surface and avoiding the modification of the surface chemistry (Velasco et al., 2019).

\section{RESULTS AND DISCUSSION}

\section{Textural and Surface Properties of the ACFs}

First, the modification of the surface chemistry of the carbon fibers by the fluorination treatment was evaluated by XPS. The XPS spectra revealed the presence of three main peaks, which correspond to F1s, O1s, and C1s. As can be seen in Table 1, the fluorine content increased as a function of partial pressure, ranging from 12 to 30 at. \% (18 to 39 wt. \%). The surface treatment slightly affected the content of oxygen, showing a meager increase for ACF A, followed by a gradual decrease with the raise of the $\mathrm{F}_{2}: \mathrm{N}_{2}$ ratio. In this regard, some $\mathrm{C}-\mathrm{H}$ and $\mathrm{C}-\mathrm{C}$ bonds can be broken during the fluorination process, forming dangling bonds, which are likely to subsequently react with oxygen and moisture from air and form oxygenated surface groups (Dubois et al., 2018). The presence of oxygenated groups in the starting material may also affect the nature and stability of the C-F bonding (Matei Ghimbeu et al., 2015). On the other hand, samples B and D exhibit a similar surface composition, thus indicating a low impact of the temperature in the extent of the fluorination.

In order to evaluate the changes in the surface functional groups of the fluorinated ACFs, the C1s peaks were deconvoluted to several pseudo-Voigt functions using a peak analysis program obtained from Unipress Co, USA. More details can be found in previous works (Kim et al., 2019). The assignments and peak parameters of the different $\mathrm{C} 1 \mathrm{~s}$ components are provided in Table 2 and the deconvolution of the C1s spectra in
TABLE 1 | Surface elemental composition of the ACFs obtained from the XPS spectra.

\begin{tabular}{lccc}
\hline Sample & \multicolumn{3}{c}{ Elemental contents (at. \%) } \\
\cline { 2 - 4 } & C & O & F \\
\hline E (raw) & 90.1 & 9.9 & - \\
A (1:9) & 75.9 & 11.4 & 12.7 \\
B (3:7) & 65.8 & 10.4 & 23.8 \\
C (5:5) & 60.5 & 9.8 & 29.7 \\
D (3:7, 150 $\mathrm{C})$ & 68.5 & 9.8 & 21.7 \\
\hline
\end{tabular}

Figure 1. As expected, it is observed that fluorination changes the valence state of carbon bonding from $\mathrm{sp}^{2}$ to $\mathrm{sp}^{3}$. Also, the semi-covalent $\mathrm{C}-\mathrm{F}$ bonding markedly increases with the fluorine content, following the order $\mathrm{A}<\mathrm{B}<\mathrm{C}$. These $\mathrm{C}$ $\mathrm{F}$ bonds are essentially covalent and can result from the hyperconjugation between $\mathrm{C}-\mathrm{C}$ bonds in the non-fluorinated region and closed to C-F bonds (Sato et al., 2004). On the contrary, the different results obtained for B and D samples indicate that the formation of covalent bonding is favored by an increase of the treatment temperature. These results are in agreement with the literature (Bismarck et al., 1997; Kim et al., 2019).

The nitrogen adsorption isotherms of the ACFs (Figure 2) display important information about the impact of the fluorination treatment on the textural properties. The parent fiber (E) exhibits a type I isotherm characteristic of microporous materials. It is noticed that the increase of the fluorine content is accompanied by a progressive reduction of the microporous structure (Table 3). In this sense, while a moderate fluorine doping (ACF A) barely etches the pore walls, thus largely preserving the textural properties, more severe conditions can reduce several times the nitrogen uptake (ACF $\mathrm{C}$ ). However, the shape of the isotherm is preserved for all the fluorinated fibers indicating only a reduction of the micropore volume available due to the formation of the C-F bonds. This is further confirmed by the calculation of the average pore width by the QSDFT-slit kernel, which only shrinks from $0.61 \mathrm{~nm}$ for the initial sample to $0.57 \mathrm{~nm}$ for the fluorinated ones and it is in accordance with previous works (Lee et al., 2007). Besides, the specific density of the carbon increases due to the weight uptake after the reaction with $\mathrm{F}_{2}$. This means that the net reduction in the micropore volume due to the fluorination is actually smaller than the measured one (Setoyama et al., 1996; Parmentier et al., 2012). The volume of narrow micropores calculated from the $\mathrm{CO}_{2}$ isotherms (Table 3) confirms the previous statements.

\section{Water Sorption Behavior}

The water sorption isotherms of all the ACFs herein investigated are displayed in Figure 3A, together with a magnification of the adsorption branch at low relative humidities (Figure 3B). Therein it is observed that the fluorinated samples exhibit a quite different water sorption behavior depending on their degree of 
TABLE 2 | Parameters obtained from the deconvolution of the C1s peak of the XPS spectra.

\begin{tabular}{|c|c|c|c|c|c|c|}
\hline \multirow[t]{2}{*}{ Components } & \multirow[t]{2}{*}{ Peak position (eV) } & \multicolumn{5}{|c|}{ Concentration (at. \%) } \\
\hline & & E (raw) & A & B & C & D \\
\hline C(1) C-C(sp2) & 284.5 & 77.3 & 55.93 & 31.04 & 22.57 & 37.88 \\
\hline C(2) C-C(sp3) & 285.5 & 12.68 & 20.38 & 34.54 & 37.05 & 29.88 \\
\hline $\mathrm{C}(3) \mathrm{C}-\mathrm{O}$ & 286.4 & 6.75 & 7.11 & 6.01 & 5.68 & 5.81 \\
\hline $\mathrm{C}(4) \mathrm{C}=\mathrm{O}$ & 287.5 & 3.27 & 4.26 & 4.63 & 4.54 & 3.71 \\
\hline C(5) Semi-covalent C-F & 288.6 & - & 8.77 & 19.65 & 25.08 & 15.80 \\
\hline C(6) Covalent C-F & 290.1 & - & 3.55 & 4.13 & 4.63 & 6.92 \\
\hline
\end{tabular}

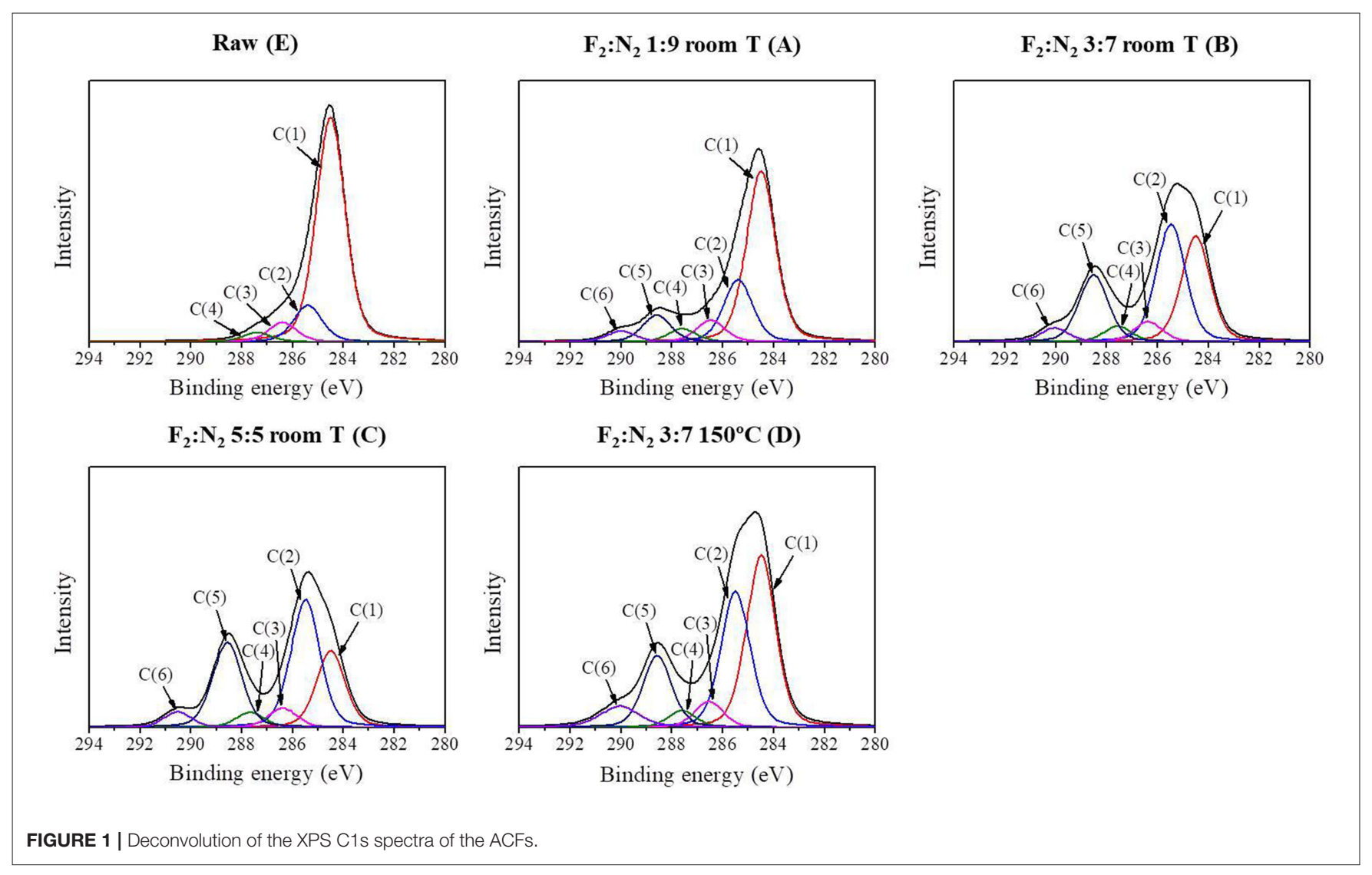

fluorination. On the one hand, the water isotherm of sample A, with the lowest fluorine content, is quite similar to the one of the raw activated carbon fiber $\mathrm{E}$. This type $\mathrm{V}$ isotherm, with a marked upswing in the water uptake at medium relative humidities followed by a more steady profile, is characteristic of microporous materials. Still, some non-negligible differences are noted: sample A shows (i) a higher water affinity at low relative humidities (see Figure 3B), (ii) a less pronounced slope of the upward curve, and (iii) a slightly lower total water uptake. Considering that the water adsorption process is initially governed by the specific interactions between the water molecules and the active sites on the carbon surface, the first point denotes an increased hydrophilicity of the material inferred by the mild fluorination. The formation of some additional oxygen groups during or after the fluorination can contribute to some extent to this enhanced water affinity, although it cannot justify such a notorious change. In this regard, the Langmuir-type equation developed by Lodewyckx et al. (2013) permits calculating the amount of oxygenated complexes of porous carbon materials by fitting the first points of the water adsorption isotherm, assuming these are the only type of surface groups playing a role. By applying this model, a value of $19.9 \%$ wt. is obtained for sample A, far from the XPS result (13.6\% O wt.) (Table 4). Thus, it seems that this increased hydrophilicity can be mainly ascribed to the presence of the fluorine atoms. The second point indicates a slower filling of the micropores, probably due to increased internal barriers for water diffusion in the fluorinated system (Farmahini et al., 2015). However, it has to be noted that these barriers can only 


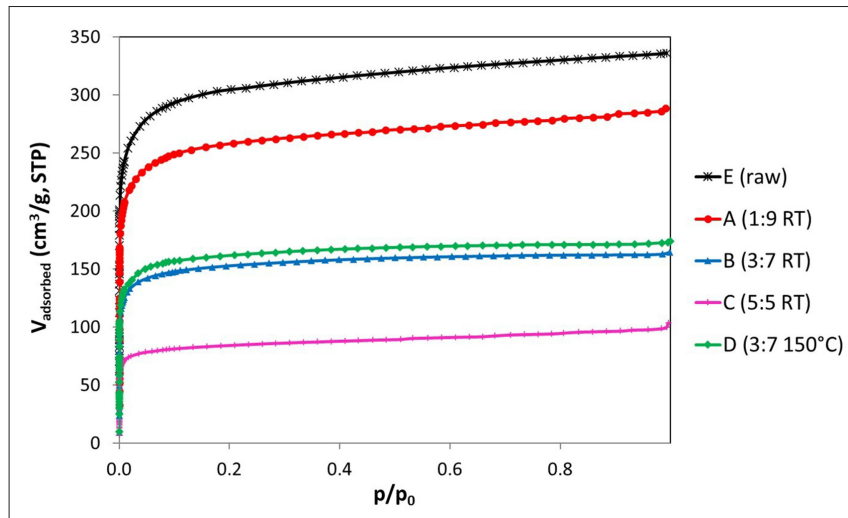

FIGURE $2 \mid \mathrm{N}_{2}$ adsorption isotherms at $-196^{\circ} \mathrm{C}$ of the ACFs outgassed at $150^{\circ} \mathrm{C}$.

TABLE 3 | Textural parameters obtained from the $\mathrm{N}_{2}$ and $\mathrm{CO}_{2}$ adsorption isotherms at -196 and $0^{\circ} \mathrm{C}$, respectively.

\begin{tabular}{|c|c|c|c|c|}
\hline \multirow[b]{2}{*}{ Sample } & \multicolumn{3}{|c|}{$\mathbf{N}_{2}$} & \multirow{2}{*}{$\frac{\mathrm{CO}_{2}}{\mathrm{~W}_{0}\left(\mathrm{~cm}^{3} / \mathrm{g}\right)}$} \\
\hline & $\mathbf{V}_{\text {micropores }}\left(\mathrm{cm}^{3} / \mathrm{g}\right)$ & $V_{t}\left(\mathrm{~cm}^{3} / \mathrm{g}\right)$ & $\mathrm{S}_{\mathrm{BET}}\left(\mathrm{m}^{2} / \mathrm{g}\right)$ & \\
\hline$E$ & 0.44 & 0.54 & 1,194 & 0.325 \\
\hline$A$ & 0.38 & 0.45 & 1,011 & 0.286 \\
\hline B & 0.24 & 0.25 & 600 & 0.181 \\
\hline C & 0.14 & 0.15 & 331 & 0.105 \\
\hline D & 0.25 & 0.27 & 606 & 0.189 \\
\hline
\end{tabular}

delay but not hamper the sorption of water, since the drop in the total water uptake after the mild fluorination is only of around $3 \%$ (point iii). As a matter of fact, this is the only doped fiber that presents a higher ratio of pore volume obtained from water vapor adsorption to total pore volume measured by nitrogen than the original fiber E.

Similar water isotherms were gathered for samples B and D but following a different pattern than that of ACFs A and E. In this case, the most noticeable water uptake occurs at high relative pressures $(>0.65)$, preceded by an initial rise and a subsequent plateau. In accordance with the textural data, sample D leads to a slight higher total water uptake. Though, an opposite trend is observed at low relative humidities (Figure 3B). Bearing in mind their similar fluorine and oxygen contents, this seems to be related to the variances in the amount of covalent and semicovalent C-F bonds in each material. In particular, sample D has more covalent C-F bonds than B (6.92 vs. $4.13 \%$, respectively) and less semi-covalent (15.8 vs. 19.7\%). It has already been established that larger dipoles of the ionic or semi-covalent C-F bond provide greater polarity than that of the covalent C-F bond (Nakajima, 1994). Also, the influence of the probable presence of hydrophobic-CF2 of -CF3 bonds cannot be disregarded.

In line with the textural parameters calculated from the nitrogen isotherms, sample $\mathrm{C}$, with the highest extent of fluorination, shows the lowest capacity for water adsorption at all the relative vapor pressures.
According to Table 4, if the model based on the only influence of oxygen is applied again, the oxygen content calculated from the water isotherm for sample $\mathrm{C}$ is lower than the XPS value, suggesting an increased hydrophobicity. However, there are other variables that could play a role. For example, steric effects, as those reported for highly oxygenated carbon materials (Velasco et al., 2016), could exist, leading to a decrease of the number of water molecules in the cluster or even avoiding the formation of the cluster. In the case of samples B and D, both the calculated and the experimental amount of oxygenated complexes are similar, which can lead to the misleading conclusion that the fluorine is not participating in the water affinity of these samples. Nevertheless, a very probable scenario would be that the two effects identified for fibers A (hydrophilicity given by the fluorine) and $\mathrm{C}$ (steric hindrance) are counteracting each other. This somehow intermediate performance is in line with the inbetween fluorine content of samples $\mathrm{B}$ and $\mathrm{D}$ with respect to $\mathrm{A}$ and $C$ fibers. Summing up, the trend in calculated oxygen against real oxygen for all samples evidences the supplementary influence of the fluorine on the water adsorption.

On the other hand, the desorption branch of the water isotherms of these three samples goes to slightly negative values. This indicates some mass loss. It is highly probable that some labile C-F bonds are present in the surface of the materials, especially in the case of fluorination at low temperatures and during short times, and react with the water molecules to form hydroxyl groups (Parmentier et al., 2012). This could also explain the uptake of water at high relative humidities of these samples.

\section{Water Cycles}

In order to further investigate and to check the stability of the fluorine doped ACFs under humid conditions, consecutive water isotherms were measured. The results are presented in Figure 4. Therein a slight increase in the water uptake of sample A is noticed, most probably due to a minor oxygenation of the surface (see Table 4). On the contrary, the rest of the fibers show a much more marked change of the adsorption profile. More in detail, the hysteresis loops nearly disappear in the second cycle and the adsorption/desorption branches practically overlap with the adsorption branch of the initial isotherm. Furthermore, there is a slight decrease of the total water uptake in the second cycle, due to the flattening of the adsorption curve at very high relative humidities. This could confirm our previous hypothesis of the reaction of the water molecules with the labile $\mathrm{C}-\mathrm{F}$ bonds at very high vapor pressures during the first cycle. In the second cycle, no labile C-F bonds were left for reaction with water. Also, there is a non-negligible raise in the oxygenated species calculated from the water isotherms (Table 4) between the first and the second cycle. Since no changes were recorded in the nitrogen isotherm of these fibers after the first water cycle, this shift in the profile of the water isotherms seem to be only caused by alterations of the surface chemistry that facilitate the penetration of the water molecules in the porous network.

An additional 3rd water cycle was performed on the highly fluorinated samples B, C, and D, obtaining essentially the same 

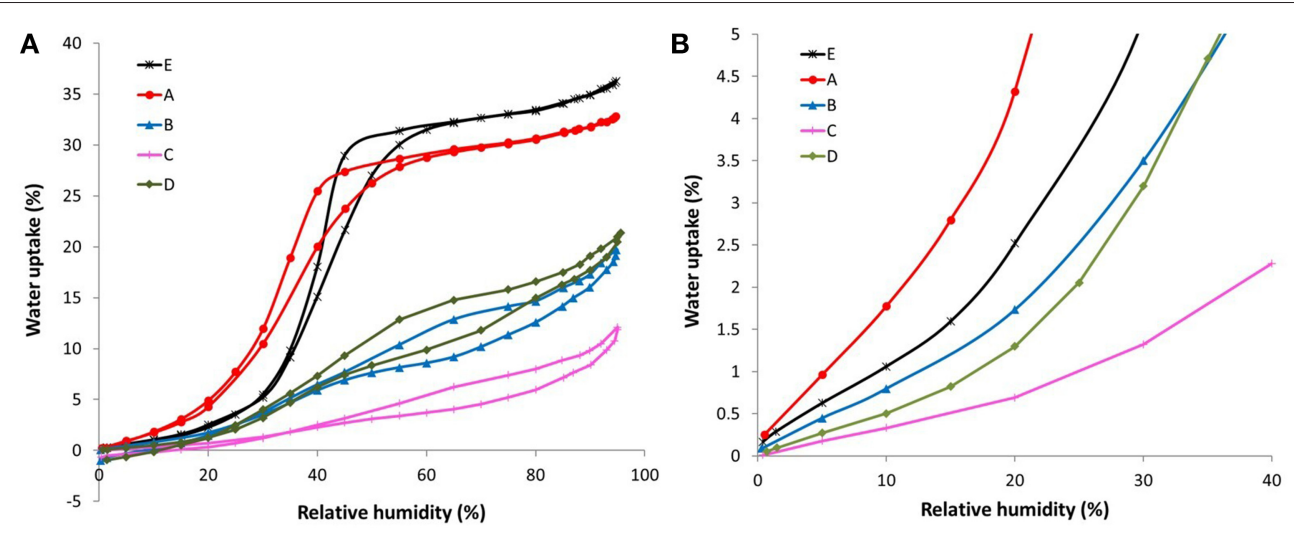

FIGURE 3 | (A) Complete and (B) low pressure range of the $\mathrm{H}_{2} \mathrm{O}$ sorption isotherms at $20^{\circ} \mathrm{C}$ of the ACFs.

TABLE 4 | Comparison between the XPS oxygen contents and the ones calculated from the water sorption isotherm (\% weight).

\begin{tabular}{|c|c|c|c|}
\hline & \multirow[t]{2}{*}[\mathrm{O}]{$_{X P S}$} & \multicolumn{2}{|c|}{$[\mathrm{O}]_{\text {waterisotherm }}$} \\
\hline & & 1st water cycle & 2nd water cycle \\
\hline$E$ & 12.8 & 13.0 & - \\
\hline A & 13.6 & 19.9 & 21.4 \\
\hline B & 11.8 & 12.1 & 13.5 \\
\hline C & 10.8 & 8.3 & 9.6 \\
\hline$D$ & 11.2 & 10.7 & 13.8 \\
\hline
\end{tabular}

isotherms as those of the 2 nd cycle. This will be further discussed in the next section.

\section{Kinetics}

Water vapor adsorption kinetics in porous carbon materials are dependent on both the pore size and the functionality of the carbon surface (Fletcher et al., 2007). Since the fluorinedoped fibers present the same average pore width, any differences in the kinetic profiles need to be assessed in terms of the surface chemistry.

The Linear Driving Force (LDF) model was used in order to study the kinetics of water adsorption in the ACFs $\left(R^{2}>0.99\right)$. The kinetic profiles thus estimated are shown in Figure 5A. For ACF A, a typical profile of water adsorption in microporous pitch-based activated carbon fibers is obtained (Ito et al., 2015). This implies that the rate constant of water adsorption initially decreases with increasing water vapor pressure until it reaches a minimum, which is coincident with the steepest water uptake, then raises again as the isotherm is getting flatter and there is a sharp decrease at high relative humidities as a result of a small change in the slope of the isotherm. Thus, the rate-determining step is related to the formation of water molecular assemblies. This agrees with previous works where it was found that slower kinetic rates are assigned to associative hydrogen bonding of water molecules to adsorbed water (Fletcher et al., 2007). For the other fluorinated ACFs the first minimum is reached approximately at the same relative pressure than for sample A but with a less marked character. Then, the subsequent kinetic profile is displaced to lower relative humidities, so that the amplitude of the peak matches with the plateau of the water sorption curve, and then there is a fall of the adsorption rate to the actual minimum. Another interesting observation is that the kinetic rates at the first stages of the water sorption process, where the surface chemistry plays the most important role, follow the order $\mathrm{A}<\mathrm{B} \leq \mathrm{D}<\mathrm{C}$. Taking into consideration that the adsorption kinetics are slower when the adsorbate-adsorbent interactions are stronger (Fletcher et al., 2007; Jia et al., 2017), this corroborates our previous findings about the hydrophilic/hydrophobic nature of the studied ACFs: while the mild fluorinated ACF (A) presents a marked hydrophilic performance, the one with the highest fluorine surface coverage (C) leads to the weakest surface interactions, thus to a hydrophobic behavior.

Finally, the kinetic profiles of the consecutive water adsorption cycles of the ACF with the highest fluorine content (C) were also compared (Figure 5B). The changes in the surface chemistry produced by the exposure of the sample to one water sorption cycle, varied the kinetics of the adsorption process as well. In fact, the kinetic profile of cycles 2 and 3 resembles that of sample A, typical of a continuous micropore filling. Moreover, the adsorption rate at low relative humidities slows down after the first cycle, supporting again the formation of surface groups with higher water affinity. The same trends were also found for fibers B and $\mathrm{D}$.

Summing up, the obtained results highlight the importance of controlling the fluorination process in order to obtain porous carbon materials with the desired textural and surface features, in function of the properties of the starting material (pore width, particle size, graphitization level...) and the intended application. This will be crucial in order to guarantee an optimal efficiency and stability of the samples under humid conditions. 

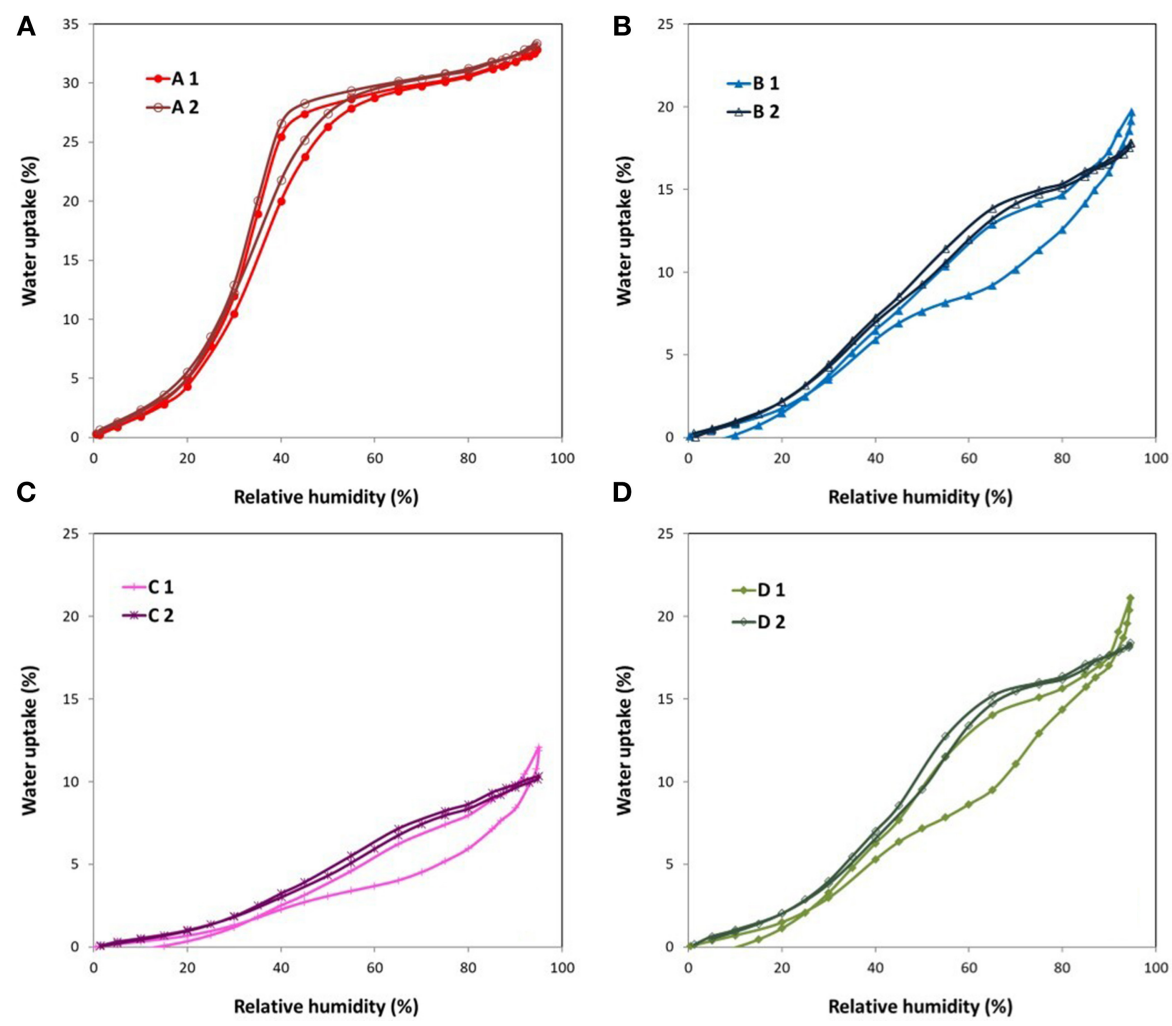

FIGURE 4 | Water cycling isotherms of the fluorinated ACFs (A) A, (B) B, (C) C, and (D) D.
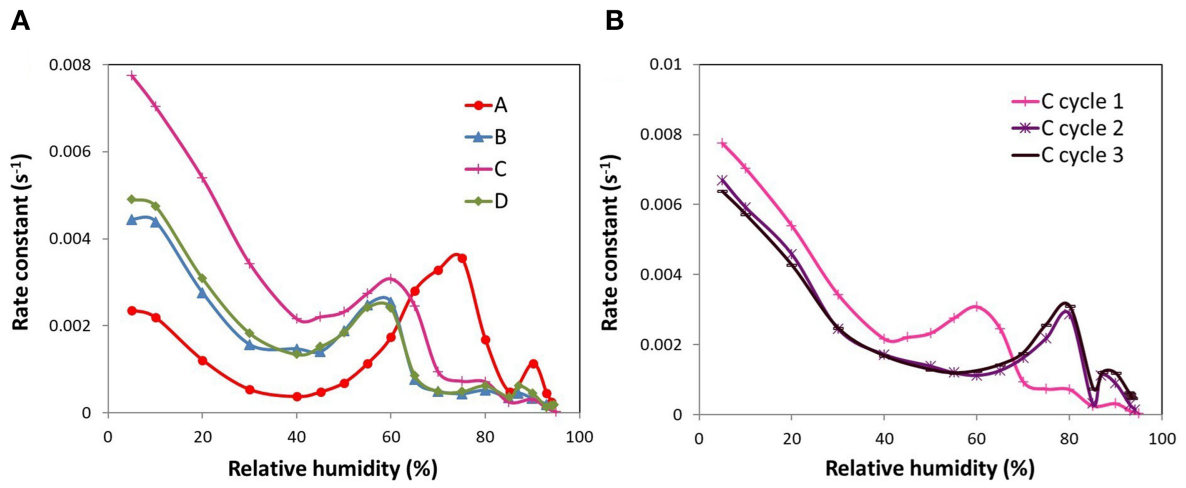

FIGURE 5 | Rate constants of the ACFs as a function of relative humidity: (A) fluorinated ACFs and (B) first to third cycle for ACF C.

\section{CONCLUSIONS}

In this work, a series of fluorine-doped pitch-based activated carbon fibers were obtained by gradually changing the partial pressure of the gas and to a minor extent, the temperature. This led to samples with varied fluorine content, $\mathrm{C}-\mathrm{F}$ type bonding and textural properties, as revealed by the information given by XPS and gas sorption isotherms. Also, water isotherms with different profiles were collected.

A mild fluorination $\left(\mathrm{F}_{2}: \mathrm{N}_{2}=1: 9\right.$, room temperature) slightly modified the textural properties of this particular parent fiber and inferred hydrophilic properties to the carbon surface. This was corroborated by a marked increase in the slope of the water isotherm at low relative pressures accompanied by 
slower kinetics, due to strong adsorbate-adsorbate interactions, in comparison with the rest of the samples. Differently, the high fluorine surface coverages obtained by using elevated fluorine gas ratios led to a decreased porosity and an increasing hydrophobic surface. In addition, the formation of labile C-F bonds was promoted and this caused a certain instability of the materials when exposed to water vapor. Raising the fluorination temperature up to $150^{\circ} \mathrm{C}$ did not have an apparent influence on the total fluorine content. However, these 2 samples exhibited a somehow different sorption behavior that can be attributed to the different nature and siting of the C-F bonds formed. These findings put into evidence that even slight changes in the reaction conditions can be decisive in the modulation of the properties of the final fluorine decorated material.

Summing up, water vapor sorption has revealed as a useful technique for the characterization of the non-straight forward porous and surface modifications induced by fluorine doping of carbon materials. The provided information will certainly contribute to widen and improve the potential applications of fluorinated activated carbon fibers.

\section{REFERENCES}

Bandosz, T. J., Jagiełł, J., Schwarz, J. A., and Krzyzanowski, A. (1996). Effect of surface chemistry on sorption of water and methanol on activated carbons. Langmuir 12, 6480-6486. doi: 10.1021/la9 $60340 \mathrm{r}$

Bismarck, A., Tahhan, R., Springer, J., Schulz, A., Klapötke, T. M., Zell, H., et al. (1997). Influence of fluorination on the properties of carbon fibres. J. Fluor. Chem. 84, 127-134. doi: 10.1016/S0022-1139(97)00029-8

Dubois, M., Batisse, N., Guérin, K., and Thomas, P. (2018). Fluorine: characteristics, chemistry and applications controlled fluorination using atomic fluorine," in Chemical Elements (Fluorine, Rhodium and Rubidium): Properties, Synthesis and Applications, ed A. Huff (Nova Science Publishers).

Farmahini, A. H., Sholl, D. S., and Bhatia, S. K. (2015). Fluorinated carbide-derived carbon: more hydrophilic, yet apparently more hydrophobic. J. Am. Chem. Soc. 137, 5969-5979. doi: 10.1021/jacs.5b01105

Fletcher, A. J., Uygur,Y., and Thomas K,M. (2007). Role of surface functional groups in the adsorption kinetics of water vapor on microporous activated carbons. J. Phys. Chem. C 111, 8349-8359. doi: 10.1021/jp070815v

Im, J. S., Jung, M. J., and Lee, Y.-S. (2009). Effects of fluorination modification on pore size controlled electrospun activated carbon fibers for high capacity methane storage. J. Colloid Interface Sci. 339, 31-35. doi: 10.1016/j.jcis.2009.07.013

Ito, H., Iiyama, T., and Ozeki, S. (2015). Kinetics of cluster-mediated filling of water molecules into carbon micropores. J. Phys. Chem. C 119, 4118-4125. doi: $10.1021 /$ jp 5118085

Jia, L., Yao, X., Ma, J., and Long, C. (2017). Adsorption kinetics of water vapor on hypercrosslinked polymeric adsorbent and its comparison with carbonaceous adsorbents. Micropor. Mesop. Mat. 241, 178-184. doi: 10.1016/j.micromeso.2016.12.028

Kim, K. H., Han, J.-I., Kang, D.-H., and Lee, Y.-S. (2018). Improved heatspreading properties of fluorinated graphite/epoxy film. Carbon Lett. 28, 96-99. doi: 10.5714/CL.2018.28.096

Kim, K. H., Kang, D. H., Kim, M. J., and Lee, Y.-S. (2019). Effect of C-F bonds introduced by fluorination on the desalination properties of activated carbon as the cathode for capacitive deionization. Desalination 457, 1-7. doi: 10.1016/j.desal.2018.12.005

Kumar, K. V., Preuss, K., Guo, Z. X., and Titirici, M. M. (2016). Understanding the hydrophilicity and water adsorption behavior of nanoporous nitrogen-doped carbons. J. Phys. Chem. C 120, 18167-18179. doi: 10.1021/acs.jpcc.6b06555

\section{DATA AVAILABILITY STATEMENT}

The raw data supporting the conclusions of this article will be made available by the authors, without undue reservation.

\section{AUTHOR CONTRIBUTIONS}

LV studied the water sorption behavior of the samples and wrote the manuscript. KK synthesized and characterized the raw and fluorinated activated carbon fibers. Y-SL and PL conceived the work and contributed to the discussion of the results. All authors contributed to the article and approved the submitted version.

\section{FUNDING}

This work was partially supported by the Korea Institute of Energy Technology Evaluation and Planning (KETEP) grant funded by the Ministry of Trade, Industry and Energy (MOTIE) of the Republic of Korea (No. 20164010201070).

Lee, Y.-S., Kim, Y. H., Hong, J. S., Suh, J. K., and Cho, G. J. (2007). The adsorption properties of surface modified activated carbon fibers for hydrogen storages. Cataly. Today 120, 420-425. doi: 10.1016/j.cattod.2006.09.014

Li, G., Kaneko, K., Ozeki, S., Okino, F., Ishikawa, R., Kanda, M., et al. (1995). Water rejective nature of fluorinated microporous carbon fibers. Langmuir 11, 716-717. doi: 10.1021/la00003a008

Liu, L., Tan, S. J., Horikawa, T., Do, D. D., Nicholson, D., and Liu, J. (2017). Water adsorption on carbon - a review. Adv. Colloid Interface Sci. 250 64-78. doi: 10.1016/j.cis.2017.10.002

Liu, Y., Jiang, L., Wang, H., Wang, H., Jiao, W., Chen, G., et al. (2019). A brief review for fluorinated carbon: synthesis, properties and applications. Nanotechnol. Rev. 8, 573-586. doi: 10.1515/ntrev-2019-0051

Lodewyckx, P. (2010), The effect of water uptake in ultramicropores on the adsorption of water vapour in activated carbon. Carbon 48, 2549-2553. doi: 10.1016/j.carbon.2010.03.032

Lodewyckx, P., Raymundo-Piñero, E., Vaclavikova, M., Berezovska, I., Thommes, M., Béguin, F., et al. (2013). Suggested improvements in the parameters used for describing the low relative pressure region of the water vapour isotherms of activated carbons. Carbon 60, 556-558. doi: 10.1016/j.carbon.2013.04.006

Matei Ghimbeu, C., Guerin, K., Dubois, M., Hajjar-Garreau, S., and VixGuterl, C. (2015). Insights on the reactivity of ordered porous carbons exposed to different fluorinating agents and conditions. Carbon 84, 567-583. doi: 10.1016/j.carbon.2014.12.034

Nakajima, T. (1994). "Fluorine-carbon and fluoride-carbon materials," in Chemistry, Physics and Applications (New York, NY: CRC Press).

Nguyen, V. T., Horikawa, T., Do, D. D., and Nicholson, D. (2014). Water as a potential molecular probe for functional groups on carbon surfaces. Carbon 67, 72-78. doi: 10.1016/j.carbon.2013.09.057

Park, M. S., Kim, K. H., Kim, M. J., and Lee, Y. S. (2016). NH3 gas sensing properties of a gas sensor based on fluorinated graphene oxide. Colloid Surf. A 490, 104-109. doi: 10.1016/j.colsurfa.2015.11.028

Parmentier, J., Schlienger, S., Dubois, M., Disa, E., Masin, F., and Centeno, T. A. (2012). Structural/textural properties and water reactivity of fluorinated activated carbons. Carbon 50, 5135-5147. doi: 10.1016/j.carbon.2012.06.054

Sato, Y., Itoh, K., Hagiwara, R., Fukunaga, T., and Ito, Y. (2004). On the socalled "semi-ionic" C-F bond character in fluorine-GIC. Carbon 42, 3243-3249. doi: 10.1016/j.carbon.2004.08.012

Setoyama, N., Li, G., Kaneko, K., Okino, F., Ishikawa, R., Kanda, M., et al. (1996). Nitrogen adsorption on fluorinated activated carbon fiber. Adsorption 2, 293-297. doi: 10.1007/BF00879544 
Shahtalebi, A., Mar, M., Guérin, K., and Bhatia, S. K. (2016). Fluorination-induced changes in hydrophobicity of silicon carbide-derived nanoporous carbon. J. Phys. Chem. C 120, 18595-18606. doi: 10.1021/acs.jpcc.6b04655

Shao, Y., Yue, H., Qiao, R., Hu, J., Zhong, G., Wu, S., et al. (2016). Synthesis and reaction mechanism of novel fluorinated carbon fiber as a high-voltage cathode material for rechargeable Na batteries. Chem. Mater. 28, 1026-1033. doi: 10.1021/acs.chemmater.5b03762

Sugiyama, H., and Hattori, Y. (2020). Selective and enhanced CO2 adsorption on fluorinated activated carbon fibers. Chem. Phys. Lett. 758:137909. doi: 10.1016/j.cplett.2020.137909

Sun, L., Gong, P., Liu, X., Pang, M., Tian, M., Chen, J., et al. (2017). Fluorinated carbon fiber as a novel nanocarrier for cancer chemo-photothermal therapy. $J$. Mater. Chem. B 5, 6128-6137. doi: 10.1039/C7TB01155E

Thommes, M., Morlay, C., Ahmad, R., and Joly, J. P. (2011). Assessing surface chemistry and pore structure of active carbons by a combination of physisorption $\left(\mathrm{H}_{2} \mathrm{O}, \mathrm{Ar}, \mathrm{N}_{2}, \mathrm{CO}_{2}\right)$, XPS and TPD-MS. Adsorption 17:653. doi: 10.1007/s10450-011-9360-4

Tóth, A., and Lászlo, K. (2012). "Water adsorption by carbons," in Hydrophobicity and Hydrophilicity, Novel Carbon Adsorbents, ed J.M.D. Tascón (Amsterdam: Elsevier), 147-171.

Touhara, H., and Okino, F. (2000). Property control of carbon materials by fluorination. Carbon 38, 241-267. doi: 10.1016/S0008-6223(99)0 0140-2
Velasco, L. F., Devos, A., and Lodewyckx, P. (2019). The importance of outgassing conditions when using water vapour to characterize activated carbons. Carbon 152, 409-415. doi: 10.1016/j.carbon.2019.06.054

Velasco, L. F., Snoeck, D., Mignon, A., Misseeuw, L., Ania, C. O., Van Vlierberghe, S., et al. (2016). Role of the surface chemistry of the adsorbent on the initialization step of the water sorption process. Carbon 106, 284-288. doi: 10.1016/j.carbon.2016.05.042

Wang, T., Zang, X., Wang, X., Gu, X., Shao, Q., and Cao, N. (2020). Recent advances in fluorine-doped/fluorinated carbon-based materials for supercapacitors. Energy Storage Mater. 30, 367-384. doi: 10.1016/j.ensm.2020.04.044

Conflict of Interest: The authors declare that the research was conducted in the absence of any commercial or financial relationships that could be construed as a potential conflict of interest.

Copyright (c) 2021 Velasco, Kim, Lee and Lodewyckx. This is an open-access article distributed under the terms of the Creative Commons Attribution License (CC BY).

The use, distribution or reproduction in other forums is permitted, provided the original author(s) and the copyright owner(s) are credited and that the original publication in this journal is cited, in accordance with accepted academic practice. No use, distribution or reproduction is permitted which does not comply with these terms. 